\title{
A LAN HOUSE COMO ESPAÇO DE APRENDIZADO E INCLUSÃO PARA ALUNOS DO ENSINO FUNDAMENTAL DO MUNICÍPIO DE BOM JESUS DA LAPA
}

\author{
Enilson Marques de Oliveira ${ }^{1}$
}

\section{RESUMO}

O presente estudo, que traz como título a Lan House como espaço de aprendizado e inclusão para alunos do Ensino Fundamental do município de Bom Jesus da Lapa, Bahia, parte da seguinte questão norteadora: qual a importância e contribuição da Lan House como espaço de aprendizado e inclusão para alunos do Ensino Fundamental do município de Bom Jesus da Lapa? Desta maneira, a pesquisa tem como objetivo central analisar no que se refere justamente a Lan House como espaço de prática e inclusão para alunos do Ensino Fundamental do município de Bom Jesus da Lapa. Deste modo, pretende-se apresentar situações vividas/percebidas na pesquisa para que possam contribuir para o suscitar de "novas" reflexões acerca da importância do uso das TICs na formação de sujeitos. Utilizamos a metodologia qualitativa de pesquisa por meio da observação, análise documental e entrevistas semiestruturadas, além de pesquisa bibliográfica. Os resultados apontam que as escolas precisa construir uma prática educativa/pedagógica que atenda/valorize as expectativas dos alunos, fazendo sempre um diálogo entre teoria, prática e a reflexão de forma contextualizada. Inserindo as ferramentas das Novas tecnologias da Informação e Comunicação no cotidiano escolar.

Palavras-chave: Lan House. Inclusão. Educação. Pratica Pedagógica. Aprendizagem.

\begin{abstract}
The present study, whose title is Lan House as a space for learning and inclusion for elementary school students in the municipality of Bom Jesus da Lapa, Bahia, starts from the following guiding question: what is the importance and contribution of Lan House as a learning space and inclusion for elementary school students in the municipality of Bom Jesus da Lapa? In this way, the research has as main objective to analyze in what exactly refers to the Lan House as a space of practice and inclusion for elementary school students in the municipality of Bom Jesus da Lapa. In this way, it is intended to present situations experienced / perceived in the research so that they can contribute to the raising of "new" reflections about the importance of using ICTs in the formation of subjects. We used the qualitative research methodology through observation, document analysis and semi-structured interviews, in addition to bibliographic research. The results show that schools need to build an educational / pedagogical practice that meets / values students' expectations, always
\end{abstract}

\footnotetext{
${ }^{1}$ É Mestre em Ciências da Educação pela Faculdade Interamericana de Ciências Sociales (FICS). Possui Graduação em Filosofia pela Universidade Católica do Salvador/Faculdade João Calvino (2011). É licenciado em Geografia pela FAVED. Está com uma Licenciatura em História em andamento, pela Universidade do estado da Bahia (UNEB). É Especialista em Gestão e Orientação Educacional pela Faculdade Darwin de Brasília; em Educação a Distância pela UNEB; em Metodologia do Ensino de Geografia e Historia pela Universidade Cândido Mendes; e em Ciências da Educação pela Faculdade Afirmativo. É professor da educação básica do município de Bom Jesus da Lapa e também do Estado da Bahia. E - mail: enilson.ma@ hotmail.com.
} 
making a dialogue between theory, practice and reflection in a contextualized way. Inserting the tools of New Information and Communication Technologies in the school routine.

Keywords: Lan House. Inclusion. Education. Pedagogical practice. Learning.

\section{RESUMEN}

El presente estudio, cuyo título es Casa Lan como espacio de aprendizaje e inclusión para estudiantes de educación básica en el municipio de Bom Jesus da Lapa, Bahía, parte de la siguiente pregunta orientadora: cuál es la importancia y aporte de Lan House como espacio de aprendizaje e inclusión de estudiantes de primaria en el municipio de Bom Jesus da Lapa? De esta manera, la investigación tiene como objetivo principal analizar en qué se refiere exactamente a la Casa Lan como un espacio de práctica e inclusión para los estudiantes de primaria del municipio de Bom Jesus da Lapa. De esta forma, se pretende presentar situaciones vividas / percibidas en la investigación para que contribuyan a la suscitación de "nuevas" reflexiones sobre la importancia del uso de las TIC en la formación de los sujetos. Utilizamos la metodología de investigación cualitativa a través de la observación, análisis de documentos y entrevistas semiestructuradas, además de la investigación bibliográfica. Los resultados muestran que las escuelas necesitan construir una práctica educativa / pedagógica que satisfaga / valore las expectativas de los estudiantes, siempre haciendo un diálogo entre teoría, práctica y reflexión de manera contextualizada. Insertar las herramientas de las Nuevas Tecnologías de la Información y la Comunicación en la rutina escolar.

Palabras clave: Lan House. Inclusión. Educación. Práctica pedagógica. Aprendizaje.

\section{INTRODUÇÃO}

O presente trabalho nasce inicialmente do desejo e da necessidade de melhor compreender no que se refere a Lan House como espaço de aprendizado e inclusão para alunos do Ensino Fundamental do município de Bom Jesus da Lapa, Bahia, Brasil. Vindo a desdobrar na seguinte questão norteadora. Qual a importância e contribuição da Lan House como espaço de aprendizado e inclusão para alunos do Ensino Fundamental do município de Bom Jesus da Lapa? Tendo como principal objetivo: Analisar a importância e contribuição da Lan House como espaço de aprendizado e inclusão para alunos do Ensino Fundamental do município de Bom Jesus da Lapa. Analisar a importância da Lan House para a difusão do conhecimento. Compreender de que forma acontece o aprendizado na Lan House.

Neste sentido, entendemos que as Lans Houses, através da internet, têm proporcionado oportunidades para que o processo ensino aprendizagem aconteça de forma mais democrática e coletiva, mediando à construção de novos saberes e novos conhecimentos que vem não só através do conhecimento tradicional, mas principalmente através de plataformas digitais, conteúdos expostos pelos aplicativos e inclusive dos jogos e interação nas redes virtuais. Isso significa que, se por um lado o conhecimento não está garantido pela 
simples transmissão de informações, por outro, não se pode, ingenuamente, partir do princípio de que a simples motivação ou disposição para aprender garantem o aprendizado.

Deste modo, a hipótese do estudo aponta que as Lans Houses são de grande valor no processo de inclusão de ensino aprendizado, quando utilizada de forma correta, porem deve se criar estratégias para trabalhar a aprendizagem de forma diferenciada, em sala de aula, utilizando as TICs. Assim, através deste estudo, esperamos compreender melhor como acontece o aprendizado nas Lans Houses? De que forma os conteúdos das redes e os jogos podem contribuir para o desenvolvimento da aprendizagem? Que influencia a participação nas redes sociais pode trazer ao indivíduo?

Destarte, a principal motivação para este estudo, é o anseio de desenvolver reflexões sobre as Lan Houses e os ambientes de aprendizagem computacionais como instrumentos promotores de um ensino de qualidade acessível a todos, espera-se que as considerações e análises impressas neste texto possam contribuir para se encontrar caminhos para que esses recursos sejam usados com proficiência, atingindo-se assim os objetivos educacionais ensejados com sua utilização.

Dessa forma, a educação, ao utilizar os modernos recursos da informática, como elemento auxiliador nos estudos, contribui para a abertura de caminhos construídos conscientemente, por meio de uma vivencia crítica e apta a enfrentar os constantes desafios de uma sociedade extremamente dinâmica.

Para atender aos objetivos propostos neste estudo foi realizada uma pesquisa de natureza qualitativa, que numa primeira instância envolveu uma pesquisa de caráter exploratório, buscando informações precisas, permitindo assim, uma melhor compreensão e definição do problema a se investigado.

Concomitantemente, e durante a quase totalidade do processo de pesquisa e elaboração do texto foi realizado uma intensa pesquisa bibliográfica com suporte em autores como Costa (2013), Almeida (2003) e Xavier (2002) com o objetivo de obter informações e uma base teórica sólida o suficiente para compreender e abordar o objeto de estudo eleito.

Sendo assim, se espera que as considerações efetuadas ao longo do presente trabalho contribuam para esclarecer dúvidas, ou levantar outros problemas e, principalmente ampliar as discussões e reflexões sobre este tão atual tema e que tem um papel relevante na sociedade contemporânea.

\section{AS TECNOÇOGIAS DA INFORMAÇÃO - LAN HOUSE E O APRENDIZADO DO} ALUNO

Nos dias atuais os avanços tecnológicos estão presentes cada vez mais e são necessários na vida dos seres humanos, e quem não acompanhar e não se atualizar não vai se sobressair enquanto profissional. $\mathrm{O}$ processo educativo vislumbrado desde suas origens mais remotas esteve vinculado com as características e necessidades educativas de cada época. A princípio, os conhecimentos eram transmitidos e reelaborados a partir da oralidade e da experiência quotidiana. Porém, na atualidade existe um grande desafio de encontrar caminho 
que integra melhor o humano e o tecnológico, de maneira que o tecnológico possa contribuir positivamente para uma sociedade mais justa e fraterna.

Nesse contexto, é perceptível que, vivemos na era do conhecimento, em uma sociedade comandada pela mídia, na qual as informações estão presentes em todos os lugares do mundo, o qual exige mais e mais de seus habitantes no sentido do saber, pois se o indivíduo for um ser analfabeto, ele poderá ser excluído dessa sociedade letrada. Para Vygotsky (1998), a interação social exerce um papel fundamental no desenvolvimento cognitivo. Assim vamos perceber que as teorias são essenciais e fundamentais para podermos entender esses processos e construir a nossa própria aprendizagem.

\begin{abstract}
A cada dia que passa, a informática vem adquirindo cada vez mais relevância na vida das pessoas. Sua utilização já é vista como instrumento de aprendizagem e sua ação no meio social vêm aumentando de forma rápida entre as pessoas. Cresce o número de famílias que possuem em suas residências um computador. Esta ferramenta está auxiliando pais e filhos mostrando-lhes um novo jeito de aprender e ver o mundo. Quando se aprende a lidar com o computador novos horizontes se abrem na vida do usuário. Hoje é possível encontrar o computador nos mais variados contextos: empresarial, acadêmico, domiciliar, o computador veio para inovar e facilitar a vida das pessoas. (MARCANSONI, 2010, p. 11).
\end{abstract}

Portanto, em espaço de aprendizagem virtual, devemos considerar importante todos os aspectos, principalmente os cognitivos. É um estudo que deve ser levado a sério, pois carece compreender como se dá os processos de aprendizagem na educação virtual e como acontece a construção do conhecimento nesses ambientes.

O ensino aprendizagem deve refletir e se basear na realidade da comunidade escolar e da comunidade de origem do educando. Por outro lado, análogo ao conhecimento do professor, há a expansão das Tecnologias de Informação e Comunicação, o que exige uma atualização mais rápida do professor e de seu modo de apreender e ensinar. Há uma necessidade de que professor e aluno conheçam os recurso existentes a aprendam a lidar com eles, de maneira que eles posam contribuir para a construção do conhecimento.

Assim, segundo Paulo Freire (1985) o centro principal que apoia o processo de educação é a inclusão do homem que se educa, porque tem consciência que é um ser incompleto que se descobre numa investigação devotada de ser mais. Desta forma, a aprendizagem constitui um dos principais objetos de preocupação dos cientistas que, nos laboratórios de Psicologia das Universidades, pesquisaram a vida mental e comportamental, pois, a maior parte dos comportamentos e conhecimentos exibidos pelos indivíduos é aprendida. Neste sentido, entendem-se que:

É preciso explorar as possibilidades comunicacionais presentes nas tecnologias de comunicação contemporâneas, compreendendo que elas implicam outra lógica e outra relação que possibilitam novos caminhos e aprendizagens. (SALES, 2010, p. 16).

Destarte, ao longo do processo de desenvolvimento, cada ser humano adquire, gradualmente, uma infinidade de competências, regras, informações e maneiras de lidar com 
as pessoas, coisas e situações, que resultam tanto de aprendizagem orientada de modo intencional, planejado, sistemático e controlado, como de processos espontâneos e até acidentais. Desta forma, existem deferentes concepções sobre o desenvolvimento.

Continuando a análise sobre as concepções de desenvolvimento, encontramos teóricos como Piaget e Vygotsky que, desde a década de 20, do século XX, iniciaram pesquisas com o objetivo de investigar a gênese do processo de construção do conhecimento e, consequentemente, o desenvolvimento do sujeito. Vygotsky (1994) enfatiza a importância do contexto sócio histórico nesse processo, o sujeito se apropria do objeto mediado pelo outro, pela sua história individual e social. Para Vygotsky, o processo de formação de pensamento é acordado e definido pelo relacionamento social e pela constante conversação que se coloca entre crianças e adultos, a qual aceita a apropriação do conhecimento de muitas gerações.

Por outro lado, o pensador Piaget (1978) vai explicar o processo evolutivo de construção da inteligência mediante períodos, que tem início quando o sujeito nasce. Pode-se dizer que toda necessidade tende: "a incorporar as coisas e pessoas à atividade própria do sujeito, isto é, assimilar o mundo exterior às estruturas já construídas, e a reajustar estas últimas em função das transformações ocorridas, ou seja, acomodá-las aos objetos externos". (PIAGET,1978, p.15)

Portanto, para Piaget, tudo o que se aprende é assimilado por uma estrutura já existente ao provocar uma reestruturação. O conhecimento se dá numa construção contínua, num processo de interação entre o sujeito e o objeto, ou seja, entre o homem e o mundo. Assim, conhecer um objeto é agir sobre e transformá-lo, apreendendo os mecanismos dessa transformação vinculados com as ações transformadoras. "Conhecer é, pois, assimilar o real às estruturas de transformações, e são as estruturas elaboradas pela inteligência enquanto prolongamento direto da ação" (PIAGET,1978, p.15). Assim, Piaget nos dar sua contribuição a respeito da compressão do entendimento do processo da aprendizagem do sujeito.

\subsection{Ressignificar a aprendizagem com o uso das novas tecnologias de informação e comunicação}

$\mathrm{Na}$ atualidade, com as vantagens da tecnologia, o homem vem obtendo um grande avanço na aquisição do conhecimento, e um dos pontos que contribui é todo esse ambiente teórico favorável e, ainda, com o desenvolvimento dos meios de comunicação eletrônicos (rádio, televisão, internet) a educação ganha um novo impulso. Melhoraram, dessa maneira, as possibilidades de transmissão do conhecimento. Portanto, é formidável olhar a epistemologia como forma de buscar fundamentos para uma análise crítica da ciência e parâmetros que permitam avaliar os resultados obtidos na pesquisa. Nessa abordagem, Aranha afirma que:

As questões da educação são engendradas nas relações que os homens estabelecem ao produzir sua existência. Neste sentido, a educação não é um fenômeno neutro, mas sofre os efeitos da ideologia, por estar de fato envolvida na política. (ARANHA, 1996, p.19)

Neste sentido, é preciso combater a mera reprodução de práticas de ensino, sem criticidade ou esforço de mudança. Faz-se necessário estar aberto às inovações e estabelecer 
diferentes métodos de trabalho, buscando suporte nas teorias da aprendizagem, porém sem perder o foco da análise individual e coletiva das práticas.

Para Perrenoud (2000,p.42), "é preciso que se criem situações que facilitem verdadeiras aprendizagens, tomadas de consciência de valores de uma identidade moral e cívica”. Já para o autor Pierre Lévy (1993, p.29), "o futuro será muito mais feito de comunicações virtuais acompanhadas de mobilidade do que o isolamento estático diante da tela".

Devemos entender que na atualidade, mais do que nuca, a educação deve comportar novas formas de aprendizagem e as tecnologias devem mediar o processo de ensino e aprendizagem. Assim, vamos perceber que aprendizagem é o processo pelo qual o ser humano se apropria do conhecimento produzido pela sociedade em que está inserido.

Nesse contexto, é compreensível que, vivemos na era do conhecimento, em uma sociedade comandada pela mídia, na qual as informações estão presentes em todos os lugares do mundo. Neste sentido a Lan House tem um lugar garantido para dar sua contribuição no aprendizado de uma geração que na maioria das vezes não tem acesso a esta tecnologia em casa. Nesse sentido, Xavier (2002) observa que,

\begin{abstract}
O crescente aumento na utilização das novas ferramentas tecnológicas (computador, Internet, cartão magnético, caixa eletrônico etc.) na vida social tem exigido dos cidadãos a aprendizagem de comportamentos e raciocínios específicos. Por essa razão, alguns estudiosos começam a falar no surgimento de um novo tipo, paradigma ou modalidade de letramento, que têm chamado de letramento digital. (XAVIER, 2002, p. 1).
\end{abstract}

Todos os indivíduos envolvidos no processo buscam por uma nova trilha, por uma construção da aprendizagem coletiva respeitando a singularidade e a identidade cognitiva de cada um, onde o uso de elementos tecnológicos é indispensável. É nessa perspectiva, que o papel da escola, mais precisamente a prática, precisa ser repensada, construindo novos caminhos mediados pelo coletivo onde todas as vozes existentes no cotidiano escolar sejam ouvidas, pois cada sujeito que faz parte do processo, possui saberes diferenciados, mas que isolados não podem transformar a escola, porem juntos ressignificam os seus saberes, construindo novos caminhos mediados pela coletividade.

Na visão de Costa (2013), a tecnologia tem contribuído para mudar a prática pedagógica, uma vez que o educador deve se preparar para lidar com essa nova realidade. Segundo esta autora,

Devido às novas exigências escolares, dentre elas a formação de indivíduos capazes de lidar com as tecnologias que surgem de forma crescente no mundo atual, mudaram bastante a ação pedagógica pelas quais o coordenador se responsabiliza, uma vez que modificaram comportamentos, atitudes, sentimentos e valores tecnológicos, mantendo-se, todavia, inalterada a necessidade de parceria entre o coordenador e o educador. (COSTA, 2013. p.5). 
Igualmente, a tecnologia moderna pode colaborar para o sucesso educativo escolar, pois a partir disso a classe discente reconstruirá conhecimentos através das ferramentas digitais que se vinculam cada vez mais nas diferenciadas situações sociais. Assim, a influência das Lans Houses deve ser trabalhada em sala para que seja aproveitado para o crescimento do aluno.

A partir disso, é vista a rapidez de conhecimentos construídos pela ação humana, seja de forma individual ou coletiva; o progresso dos produtos eletrônicos; e o avanço das descobertas tecnológicas, dentre estas, aquelas referentes à informação como, computador, tablet, smartfones cada vez mais reformulado, etc.

A Lan House, onde foi feita esta pesquisa, iniciou seu funcionamento no ano de dois mil, possui trinta computadores e é quase sempre lotada. Por mais que hoje em dia haja uma facilidade de acesso aos celulares, smartfones e tabletes com acesso à internet, nem sempre as escolas partem disso para construir conhecimentos. No entanto, podemos refletir a importância de ressignificar saberes a partir dessas ferramentas tecnológicas e, com isso, fixar as ideias de Almeida (2003) quando nos diz que,

\begin{abstract}
As TICs podem ser incorporadas na escola como suporte para: comunicação entre os educadores, pais, especialistas, membros da comunidade e de outras organizações; desenvolvimento de um banco de dados gerado na escola que dê subsídios para a tomada de decisões; criação de um fluxo de informações e troca de experiências que realimente as práticas; realização de atividades colaborativas que visam a enfrentar os problemas da realidade; desenvolvimento de projetos relacionados com a gestão administrativa e pedagógica; representação do conhecimento em construção pelos alunos e respectiva aprendizagem etc. (ALMEIDA, 2003, p. 115).
\end{abstract}

Foi observado na Lan House pesquisada, que a média de $80 \%$ dos adolescentes utiliza o computador para jogos e em seguida, para as redes sociais. Há ainda a porcentagem de $20 \%$ que utiliza a Lan House para fazerem pesquisas escolares. Neste sentido, cabe a escola, planejar atividade que contextualize a realidade destes sujeitos, pois é importante destacar que o estabelecimento de ensino também está incumbido de possibilitar esta inserção do sujeito no mundo moderno, isto é, marcado pela tecnologia constante.

Dessa maneira, o entendimento, a interação e a ressignificação dos saberes também devem surgir com base nas Tecnologias de Informação e Comunicação. Neste sentido, Costa (2013) vem dar sua contribuição, refletindo que,

\footnotetext{
Cabe destacar a utilização adequada dos instrumentos de mídia no espaço escolar, de forma que estes criem possibilidades de aprendizagem dos estudantes. Para tal o apoio pedagógico é fundamental nos momentos de planejamento do professor, pois por meio do mesmo este profissional pode perceber a relevância do uso de aparelhos tecnológicos midiáticos e, sobretudo, da abertura que estes dão à descoberta e reconstrução de conhecimentos prévios. (COSTA, 2013. p.4).
}

Nota-se, então, a necessidade de professores criarem formas de inserir recursos tecnológicos em sua prática pedagógica com a finalidade de reconstruir saberes no espaço educativo. Logo, os ambientes computacionais destinados ao ensino devem trazer à 
tona fatores com propósitos à mediação humana através das novas tecnologias da informação e comunicação. Estas têm muito a contribuir no processo de ensino-aprendizagem.

Foi observado ainda na Lan House a média de tempo gasto por adolescentes e jovens que utiliza o serviço do estabelecimento. A partir de observação do livro de registro dos frequentadores, pode se perceber que a média de tempo gasto entre logos e redes sociais e de duas horas. Porém, há registro de adolescente/jovem que chega a ficar quatro horas.

Frente a esta realidade, o processo de ensino e aprendizagem se torna expressivo na vida escolar do indivíduo, uma vez que este pode permitir atividades incluídas ao contexto social atual do sujeito em questão, favorecendo a reflexão das inúmeras informações obtidas no dia a dia, como no caso das Lans Houses, com isso contribuindo à formação crítica e autônoma de cada sujeito e, por conseguinte, à inserção deste no mundo da tecnologia universalizada.

A Internet, nesse sentido, pode ser utilizada não só na busca de informações bem como um meio a criar situações interativas com o aluno, como participação em chats, listas de discussão, videoconferências, entre outras.

Formar para as novas tecnologias é formar o julgamento, o senso crítico, o pensamento hipotético e dedutivo, as faculdades de observação e de pesquisa, a imaginação, a capacidade de memorizar e classificar, a leitura e a análise de textos e de imagem, a representação de redes, de procedimento e de estratégias de comunicação. (PERRENOUD, 2000, p.128).

A partir do exposto pelo autor, percebe-se que a internet tem proporcionado oportunidades para que o processo de ensino e aprendizagem aconteça de forma democrática e coletiva, mediando a construção de novos saberes e novos conhecimentos.

Todos os indivíduos envolvidos no processo buscam por uma nova trilha, por uma construção da aprendizagem coletiva respeitando a singularidade e a identidade cognitiva de cada um, onde o uso de elementos tecnológicos é indispensável. É nessa perspectiva, que o papel da escola, mais precisamente a prática pedagógica, precisa ser repensada, construindo novos caminhos mediados pelo coletivo onde todas as vozes existentes no cotidiano escolar sejam ouvidas, pois cada sujeito que faz parte do processo possui saberes diferenciados, mas que isolados não podem transformar a escola, porem juntos ressignificam os seus saberes, construindo novos caminhos mediados pela coletividade.

Conclui-se que, atualmente, as demandas educacionais não estão sendo atendidas de forma satisfatória pelas práticas pedagógicas tradicionais, por isso é necessário que todo o sistema educacional esteja preparado para dominar as novas tecnologias e incorporá-las a uma prática pedagógica inovadora e transformadora. Desta forma, nada melhor que o educador usar a seu favor todos os elementos disponibilizados no meio eletrônico - jogos, pesquisas, comunidades virtuais e tantas outras formas que os estudantes utilizam as novas tecnologias de informação e comunicação em seu dia a dia. 
Entendemos, portanto, que no mundo contemporâneo, aprendizagem cooperativa, interdisciplinaridade, transdisciplinaridade, currículo integrado, redes de aprendizagem e educação continuada e à distância, uso de jogos no processo educativo e, vários outros elementos que provêm das as novas tecnologias de informação e comunicação, começam a se fazer cada vez mais presentes nos ambientes acadêmicos e políticos, sobretudo quando está em pauta a discussão sobre a necessidade de renovação dos processos educacionais. Então, a escola precisa lançar mão dessas tecnologias e criar práticas novas.

\begin{abstract}
O uso de computadores, recursos audiovisuais e outras mídias mostram a convivência cada vez mais presente da comunicação oral e escrita com a comunicação eletrônica, modificando relações entre instituições e pessoas, permitindo novas formas de ver o mundo e práticas sociais mais compartilhadas. (OLIVEIRA, 2006, p.2)
\end{abstract}

Não há dúvida de que é preciso repensar a prática educativa, pensar em novas formas de aprender, criar novos espaços de aprendizagem, ou seja, "aperfeiçoar" o tempo pedagógico com aulas mais atraentes e prazerosas. Considera-se, nesse contexto, os novos espaços de aprendizagem representados pelas novas mídias, os jogos eletrônicos, os games, bem como os jogos mais antigos como o xadrez, a dama, considerados grandes estimuladores do raciocínio.

Esta nova prática implica, no entanto, nas mudanças de paradigmas educacionais, em uma nova postura do professor, no seu posicionamento frente à tecnologia digital e no seu uso na educação e na postura do aluno na condição de sujeito da própria formação.

\title{
3. CONSIDERAÇÕES FINAIS
}

O referido trabalho nos permitiu discutir acerca de uma temática relevante no contexto contemporâneo, cuja tecnologia tem se sobressaído de maneira constante. Isso foi possível a partir do levantamento, da análise e da interpretação dos dados coletados no ambiente da pesquisa - Lan House, (sujeitos da pesquisa) e da observação de campo. Assim, foram apresentados, ao longo deste escrito, quais os aspectos que marcaram o processo de ensino e aprendizagem no cotidiano escolar através das TICs.

As tecnologias da informação e da comunicação integram o conjunto das inovações que não podem mais passar despercebidas pelas instituições escolares. $\mathrm{O}$ aluno já chega à sala de aula dominando a ferramenta que ele usa para se divertir, e não necessariamente para aprender. É preciso então usá-la como recurso pedagógico a favor do processo educativo de responsabilidade da escola.

As práticas pedagógicas que utilizam as novas mídias de forma planejada permitem que o aluno desenvolva autonomia, tão fundamental no nosso mundo cada vez mais disputado, acesso à informação com rapidez e facilidade, desenvolvimento de competências de análise e reflexão, organização do pensamento, trabalho simultâneo com vários participantes em diversas partes do mundo, exposição de pensamento através de sites ou blogs, redes sociais ou até mesmo em comunidades virtuais, registro de sons e imagens e 
vídeos e, tradução de textos em várias línguas. Cabe fixar que isso tudo isso acontece por meio de um trabalho interdisciplinar. Assim, é necessário buscar a construção de uma prática educativa dinâmica e flexível, que venha atender aos anseios do contexto atual, de uma educação inserida num ambiente virtual.

Ressaltamos ainda que a finalidade da nossa pesquisa foi tecer discussões que auxiliem a outras discussões no que se refere a Lan House e seu uso na construção do conhecimento, bem como a democratização do acesso as novas tecnologias de informação e comunicação para indivíduo que busca se inserir no mundo virtual, buscando cada vez mais a melhoria na educação no nosso município, no nosso estado e no nosso país, uma vez que o trabalho não está fechado, é apenas a nossa inquietação com alguns pontos elencados com outras discussões acerca da Lan House como espaço de aprendizado e inclusão para alunos do Ensino Fundamental do município de Bom Jesus da Lapa.

\section{REFERENCIAL}

ALMEIDA, M. E. B. de. Tecnologias e gestão do conhecimento escolar. In: VIEIRA, A; ALMEIDA, M.; ALONSO, M. Gestão educacional e tecnologias. SP: Avercamp, 2003.

ARANHA, Maria Lúcia de Arruda. História da Educação, $1^{a}$ Ed. São Paulo: Moderna, 1996

COSTA, T. S. Coordenação Pedagógica e Novas Tecnologias: Em Questão, O Letramento Digital. Monografia apresentada ao Departamento de Ciências Humanas e Tecnologias da Universidade do Estado da Bahia - UNEB, Bom Jesus da Lapa, Bahia. 2013.

FREIRE, Paulo. Comunicação ou Extensão? 10ª edição. Rio de Janeiro: Paz e Terra, 1985.

LÉVY, Pierre. As tecnologias da inteligência: o futuro do pensamento na era da informática. Tradução de Carlos I, da Costa. Rio de Janeiro, Editora 34, 1993.

MARCANSONI, Micheli. Práticas educativas apoiadas com suporte da informática na educação: uma análise do processo e das perspectivas educacionais. Disponível em: http://docs.google.com/viewer?a=v\&q=cache:AFBrPgugfzkJ:www.unematnet.br/prof/foto_p_ downloads/fot_1898maucansoni_pdf. Acessado em: 05/06/2018

OLIVEIRA, Maria Olivia de Matos. Educação, Demandas Tecnológicas e Ressignificação da Prática Educativa. Artigo apresentado no EPENN, 2006.

PIAGET, Jean. Seis estudos de psicologia. Tradução Maria Alice Magalhães D'Amorim e Paulo Sérgio Lima Silva, Rio de Janeiro: Editora Forense Universitária, 1978.

PIMENTA, Selma G. Elsa; MOURA, Manoel. Pesquisa colaborativa na escola como abordagem facilitadora para o desenvolvimento profissional do professor. In: MARIN, Alda I. (org). Educação continuada. Campinas: Papirus, 2000.

PERRENOUD, Philippe. Dez Novas Competências para ensinar, Porto Alegre. Artes Médicas Sul, 2000. 
SALES, Mary Valda Souza; VALENTE, Vânia Rita; ARAGÃO, Cláudia. Educação e Tecnologias da Informação e Comunicação. Salvador: UNEB/EAD, 2010.

VYGOTSKY, Lev S. A Formação Social da Mente. São Paulo, Martins Fontes, 1998.

VYGOTSKY, L.V. A formação Social da mente: o desenvolvimento dos processos psicológicos superiores. Org. Michael Cole; tradução José Cipolla Neto. São Paulo, Martins Fontes, 1994.

XAVIER, Antônio Carlos dos Santos. Letramento Digital e Ensino. 2002. Disponível em:http://www.ufpe.br/nehte/artigos/Letramento\%20digital\%2 0e\%20ensino.pdf. Acessado em: 10/06/2020. 